\title{
Characterization of xylose reductase from the yeast Pichia stipitis: evidence for functional thiol and histidyl groups
}

\author{
Steven R. WebB and Hung LeE* \\ Department of Environmental Biology, University of Guelph, Guelph, Ontario, Canada N1G 2WI
}

(Received 24 February 1992; revised 29 May 1992; accepted 5 June 1992)

\begin{abstract}
Xylose reductase (EC 1.1.1.21) from the yeast Pichia stipitis NRC 2548 was purified to homogeneity via a twostep protocol using anion-exchange and gel-filtration chromatography. The pH-activity profile revealed the presence of two ionizable groups with $\mathrm{p} K_{\text {app }}$ values of 5.8 and 8.1, suggesting the catalytic involvement of histidyl and thiol groups, respectively. Additional evidence supporting the involvement of these residues was provided by the use of group-specific inhibitors. The enzyme was rapidly inactivated in a pseudo-first order manner by the thiolspecific modifier p-chloromercuriphenylsulphonate (PMBS) and analysis of the order-of-reaction suggested that one essential cysteine residue was modified to effect inactivation. Treatment of the enzyme with another thiolspecific modifier, 5,5'-dithiobis-(2-nitrobenzoic acid) (DTNB), showed that modification of one cysteine per monomer led to $90 \%$ loss of activity, further supporting the existence of one essential cysteine residue. Inactivation by PMBS was reversed by adding $1 \mathrm{mM}-\beta$-mercaptoethanol. Inactivation of xylose reductase by the histidinespecific modifier diethylpyrocarbonate (DEP) followed a pseudo-first order process, and analysis of the order-ofreaction suggested that one essential histidine residue was modified to effect inactivation. Treatment of DEPinactivated enzyme with $0.2 \mathrm{M}$-neutral hydroxylamine resulted in the recovery of $45 \%$ of enzyme activity. Protection of xylose reductase from PMBS- and DEP-inactivation was provided by NADPH and NADH but not by NADP ${ }^{+}$, D-xylose or DL-glyceraldehyde. This suggests that the essential histidine and cysteine residues may be involved with binding of cofactor by the $P$. stipitis xylose reductase.
\end{abstract}

\section{Introduction}

D-Xylose, the predominant pentose sugar in plant hemicelluloses, is second only to D-glucose in natural abundance. These sugars represent the majority of all carbohydrates obtained from the hydrolysis of renewable plant biomass, and their efficient utilization is essential for the development of viable biomass to energy conversion processes (Schneider, 1989).

D-Xylose metabolism in pentose-fermenting yeasts proceeds initially through a D-xylose-inducible enzyme pathway (Webb \& Lee, 1990). D-Xylose undergoes a twostep isomerization where it is first reduced by $\mathrm{NAD}(\mathrm{P}) \mathrm{H}$-dependent xylose reductase to xylitol, which is oxidized by $\mathrm{NAD}^{+}$-dependent xylitol dehydrogenase to D-xylulose. D-Xylulose is then phosphorylated by xylulose kinase to D-xylulose-5-phosphate which enters

* Author for correspondence. Tel. (519) 8244120 ext. 3828; fax (519) 837 0442; email evblee@vm.uoguelph.ca.

Abbreviations: DEP, diethylpyrocarbonate; DTNB, 5,5'-dithiobis(2-nitrobenzoic acid); PMBS, $p$-chloromercuriphenylsulphonate. the pentose phosphate, Embden-Meyerhof or phosphoketolase pathways (Evans \& Ratledge, 1984; Skoog \& Hahn-Hagerdal, 1988). Xylose reductase, the first enzyme in the pathway, has been shown to control the rate of D-xylose utilization (Hagedorn \& Ciriacy, 1989; Schneider et al., 1989). In addition, the ability of some pentose-fermenting yeasts such as Pichia stipitis to ferment D-xylose anaerobically is linked to the NADPH or NADH cofactor requirement of their xylose reductases (Bruinenberg et al., 1984).

Although xylose reductases have been purified from several yeasts (Bolen et al., 1985, 1986; Ditzelmuller et al., 1984; Ho et al., 1990; Rizzi et al., 1988; Scher \& Horecker, 1966; Suzuki \& Onishi, 1975; Verduyn et al. 1985; Watson et al., 1969) and the amino acid sequence of the $P$. stipitis xylose reductase has recently been published (Amore et al., 1991; Hallborn et al., 1991; Takuma et al., 1991), little is known about the enzyme's catalytic mechanism or the nature of its catalytic sites. Yeast xylose reductases have been classified as members of the aldose reductase enzyme family (alditol: NAD(P) ${ }^{+}$ 1-oxidoreductase, EC 1.1.1.21) based on similar sub- 
strate specificities (Bolen et al., 1986; Verduyn et al., 1985 ) and response to some chemical inhibitors (Webb \& Lee, 1991). Aldose reductases are extensively distributed in various mammalian tissues, where they reduce $D^{-}$ glucose to sorbitol. Under non-physiological conditions this activity has been implicated in the manifestation of serious diabetic complications (Kador et al., 1985). Therefore, there is considerable interest in the properties of mammalian aldose reductases, with the objective of developing more potent and specific inhibitors for the pharmacological management of these complications (Das \& Srivastava, 1985; Kador et al., 1985).

The relationship between yeast xylose reductase and mammalian aldose reductase is of interest from an evolutionary viewpoint. In the present paper, we use group-specific modifiers to provide evidence of the possible involvement of histidyl and thiol residues in the catalytic mechanism of xylose reductase from $P$. stipitis. The involvement of these residues in the catalytic mechanism of aldose reductases from mammalian sources has also been suggested (Bhatnagar et al., 1989; Cromlish \& Flynn, 1983; Doughty \& Conrad, 1982; Doughty et al., 1982; Flynn et al., 1981; Jedziniak \& Kinoshita, 1971; Liu et al., 1989; Wermuth et al., 1982).

\section{Methods}

Micro-organism. Pichia stipitis NRC 2548 (NRRL-Y7124) was kindly supplied by $R$. K. Latta, National Research Council Culture Collection, Ottawa, Ontario, Canada. The yeast was maintained at $4{ }^{\circ} \mathrm{C}$ on potato dextrose agar (PDA) slants (Difco) and subcultured prior to growth in a liquid medium (Webb \& Lee, 1991).

Preparation of inocula. A single colony from a $24 \mathrm{~h}$ PDA plate was transferred to $20 \mathrm{ml}$ medium containing $0.67 \%$ yeast nitrogen base (YNB, Difco) without amino acids and $2 \%(\mathrm{w} / \mathrm{v})$ glycerol (Bicho et al., 1988). The culture was incubated for $48 \mathrm{~h}$ at $30^{\circ} \mathrm{C}$ in a $125 \mathrm{ml}$ Erlenmeyer flask, shaken at 200 r.p.m. in a gyratory shaker (Webb \& Lee, 1991).

Culture conditions. Two millilitres of inoculum were transferred to $100 \mathrm{ml}$ medium containing $0.67 \%$ YNB without amino acids and $4 \%$ (w/v) D-xylose. The culture was kept in a $250 \mathrm{ml}$ Erlenmeyer flask and incubated as above. The cells were harvested during late exponential phase $(18-20 \mathrm{~h})$ by centrifugation and stored as a frozen pellet at $-15^{\circ} \mathrm{C}$ until use (Webb \& Lee, 1991). Cell pellets were never stored for more than one week.

Purification of xylose reductase. Unless otherwise stated, all steps were carried out at $2-4^{\circ} \mathrm{C}$. (a) Preparation of cell extract. The cell pellet from about $20 \mathrm{~g}$ wet cells was thawed and resuspended in sufficient icecold $20 \mathrm{mM}$-Bis-Tris buffer ( $\mathrm{pH} 6.5$ ) containing $0.5 \mathrm{mM}$-EDTA and $1 \mathrm{mM}$ - $\beta$-mercaptoethanol (Buffer A) to form a thin paste. About $1.5 \mathrm{~g}$ alumina (Sigma) was added, and cell extracts were prepared by breaking the cells by sonication (Webb \& Lee, 1991), followed by centrifugation (Lee et al., 1986). (b) Anion-exchange chromatography. The cell extract was applied to a DEAE-Sephacel column $(2.6 \times 20 \mathrm{~cm}$, Pharmacia) which had been previously equilibrated with Buffer $A$ at $30 \mathrm{ml} \mathrm{h}^{-1}$. The absorbed xylose reductase was eluted with $400 \mathrm{ml}$ of a 0 to $0.5 \mathrm{M}$ linear $\mathrm{NaCl}$ gradient in Buffer A. Fractions (each $5 \mathrm{ml}$ ) were collected and their $A_{280}$ measured. Fractions containing xylose reductase activity were pooled and desalted through an Econo-Pac 10DG column (Bio-Rad) into Buffer B, which contained $50 \mathrm{~mm}$-sodium sulphate, $20 \mathrm{~mm}$-sodium dihydrogen phosphate, $\mathrm{pH} 6.8$, and $1 \mathrm{~mm}-\beta$ mercaptoethanol, (c) Gel permeation chromatography. Xylose reductase was further purified using a Bio-Sil SEC 250 column (Bio-Rad) and was eluted with Buffer $B$ at $0.5 \mathrm{ml} \mathrm{min}{ }^{-1}$ at $22^{\circ} \mathrm{C}$. Fractions $(1 \mathrm{ml})$ were collected and their $A_{280}$ was measured. Fractions containing enzyme activity were pooled and stored at $4^{\circ} \mathrm{C}$.

Gel electrophoresis. The purity of xylose reductase preparations was assessed using $15 \%(\mathrm{w} / \mathrm{v})$ polyacrylamide gel electrophoresis (SDSPAGE) by the method of Laemmli (1970). SDS-PAGE was carried out at $150 \mathrm{~V}$ for $40-60 \mathrm{~min}$ in a Bio-Rad Mini Protean II Gel Electrophoresis apparatus. The proteins were stained with $0.1 \%$ Coomassie Brilliant Blue R-250 and destained with $40 \%(\mathrm{v} / \mathrm{v})$ methanol and $10 \%(\mathrm{v} / \mathrm{v})$ acetic acid until the background was clear. In some instances, gels were also stained with silver nitrate using the Bio-Rad silver-staining kit.

Analytical methods. Xylose reductase activity was determined at $25^{\circ} \mathrm{C}$ as previously described (Webb \& Lee, 1991) with some modifications. The standard assay volume of $1 \mathrm{ml}$ contained $50 \mathrm{~mm}^{-}$ potassium phosphate buffer, $\mathrm{pH} 6 \cdot 5,0 \cdot 1 \mathrm{mM}-\mathrm{NADPH}$ or $\mathrm{NADH}$, and $100 \mathrm{mM}$-D-xylose or $50 \mathrm{~mm}$-DL-glyceraldehyde. In most instances, the reaction was started by adding an appropriate amount of enzyme and activity was followed spectrophotometrically by monitoring the initial rate of decrease in $A_{340}$. One unit (U) of activity was defined as the amount of enzyme which oxidized $1 \mu \mathrm{mol}$ NADPH or NADH per min. Specific activity was based on protein determined by the method of Bradford (1976) with bovine serum albumin as the standard.

Chemical modification of xylose reductase. (a) Effect of $\mathrm{pH}$ on xylose reductase-catalysed reaction. The kinetic properties of xylose reductase were determined over the $\mathrm{pH}$ range 4.0-10.6 using the following buffers: $100 \mathrm{~mm}$-citric acid $/ \mathrm{Na}_{2} \mathrm{HPO}_{4}$ (pH $\left.4 \cdot 0-6.4\right), 100 \mathrm{mM}$ $\mathrm{KH}_{2} \mathrm{PO}_{4} / \mathrm{NaOH}(\mathrm{pH} \mathrm{6.0-8.0)}, 100 \mathrm{~mm}-\mathrm{Tris} / \mathrm{HCl}(\mathrm{pH} 7.5-8.9)$ and $100 \mathrm{~mm}$-glycine $/ \mathrm{NaOH}(\mathrm{pH} 8 \cdot 6-10 \cdot 6)$. The effect of $\mathrm{pH}$ was determined by adding $37.5 \mathrm{nM}$-xylose reductase at various substrate (Dxylose or DL-glyceraldehyde) concentrations into buffer at the $\mathrm{pH}$ being evaluated, in a total volume of $1 \mathrm{ml}$. Substrate (D-xylose) concentration was varied in the presence of saturating NADPH $(0.2 \mathrm{mM})$ concentrations. The molarity of xylose reductase was estimated using a molecular mass of $64000 \mathrm{Da}$ as determined by Verduyn et al. (1985) and Rizzi $e t$ al. (1988). Substrate-dependency data were plotted on Eadie-Hofstee plots to calculate $V_{\max a p p}$. (b) Modification of cysteine residues by p-chloromercuriphenylsulphonate $(P M B S)$. Solutions $(1 \mathrm{ml})$ containing $0.36 \mu \mathrm{M}$-xylose reductase in $10 \mathrm{~mm}$-Tris/ $\mathrm{HCl}$ buffer, $\mathrm{pH} 8.0$, were incubated with the indicated concentrations of PMBS for $120 \mathrm{~min}$ at $25^{\circ} \mathrm{C}$. The modifications were carried out under pseudo-first order conditions. Samples $(10 \mu \mathrm{l})$ were removed from the incubation mixture at specified intervals and added immediately to cuvettes containing the assay mixture for determination of enzyme activity. The reversibility of PMBS-inactivated xylose reductase was measured by adding $1 \mathrm{~mm}-\beta$ mercaptoethanol to the incubation mixture and then following the recovery of enzyme activity thereafter at specified intervals. Various compounds were tested for ability to protect the enzyme from inactivation by PMBS. These experiments were conducted as above except that the test compound was included in the incubation mixture for 4 min prior to the addition of PMBS. The compounds tested were NADPH, NADH, NADP+, D-xylose and DL-glyceraldehyde. In all experiments, controls which did not contain modifying reagents were included, and fractional activity of the modified enzyme at any given time was calculated relative to the appropriate control. (c) Modification of cysteine residue by 5,5'-dithiobis-(2-nitrobenzoic acid) (DTNB). To assess the number of thiol groups modified to effect inactivation, $1 \mathrm{ml}$ solutions containing $1.2 \mu \mathrm{M}$-xylose reductase in $10 \mathrm{mM}$-Tris/ $\mathrm{HCl}$ buffer, 
pH 8.0, were incubated with $0 \cdot 2 \mathrm{mM}$-DTNB for $80 \mathrm{~min}$ at $25^{\circ} \mathrm{C}$. Modifications were carried out under pseudo-first-order conditions. To assay for enzyme activity, $10 \mu \mathrm{l}$ aliquots were removed from the incubation mixture at various times and added immediately to cuvettes containing the assay mixture as described above. In all experiments, controls which did not contain DTNB were included and fractional activity of the modified enzyme at any given time was calculated relative to the appropriate control. The change in $A_{412}$ was monitored at $25^{\circ} \mathrm{C}$ for $80 \mathrm{~min}$, and the number of cysteine groups modified was estimated by formation of thionitrobenzoate anion using a molar extinction coefficient $(\varepsilon)$ at $412 \mathrm{~nm}$ of $1.36 \times 10^{4} \mathrm{M}^{-1} \mathrm{~cm}^{-1}$ (Ellman, 1959). (d) Modification of histidine residues by diethylpyrocarbonate $(D E P)$. Modification of histidine residues was carried out at $25^{\circ} \mathrm{C}$ by incubating xylose reductase $(0.24 \mu \mathrm{M})$ with the indicated concentrations of DEP in $50 \mathrm{~mm}$-potassium phosphate buffer, $\mathrm{pH} 6.0$. The DEP was freshly diluted to the desired concentrations in ice-cold absolute ethanol prior to each experiment. Samples $(10 \mu \mathrm{l})$ were removed from the incubation mixture at various intervals and added to cuvettes containing the assay mixture for determination of enzyme activity. Recovery of enzyme activity from DEP inactivation was assayed with $0.2 \mathrm{M}$-neutral hydroxylamine. Protection of xylose reductase activity by substrates or substrate analogues from DEP inactivation was done as described above. The final concentration of ethanol in the incubation mixture was $5 \%(\mathrm{v} / \mathrm{v})$ and this concentration was included in the controls.

Data analysis. All experiments were repeated two to five times. In each instance, similar trends were observed.

\section{Results and Discussion}

\section{Xylose reductase purification}

Previous studies have shown that $P$. stipitis contains a single xylose reductase enzyme which can utilize either NADPH or NADH as cofactor. The enzyme is a dimer composed of two identical $32 \mathrm{kDa}$ subunits (Verduyn $e t$ al., 1985; Rizzi et al., 1988). Recent genetic analysis of $P$. stipitis has confirmed that xylose reductase activity arises from a single gene which encodes a $32 \mathrm{kDa}$ product (Hagedorn \& Ciriacy, 1989; Takuma et al., 1991). Although the functional enzyme is a dimer, previous studies have found no evidence of allosteric interaction between the two subunits (Rizzi et al., 1988; Verduyn et al., 1985; Webb \& Lee, 1991).

Earlier protocols developed by Verduyn et al. (1985) and Rizzi et al. (1988) to purify the $P$. stipitis xylose reductase required four and six steps, respectively. In the present study, xylose reductase was purified to homogeneity on SDS-PAGE gels in two steps. The first chromatographic step employed a DEAE-Sephacel anion-exchange column under conditions suitable for binding xylose reductase. Anion-exchange chromatography separated the cell extract into three major protein peaks (Fig. 1). The majority of xylose reductase activity (about $68 \%$ of the amount applied) was associated with the upswing arm of the first protein peak. The pooled fractions (nos $16 \& 17$, Fig. 1) exhibited specific xylose

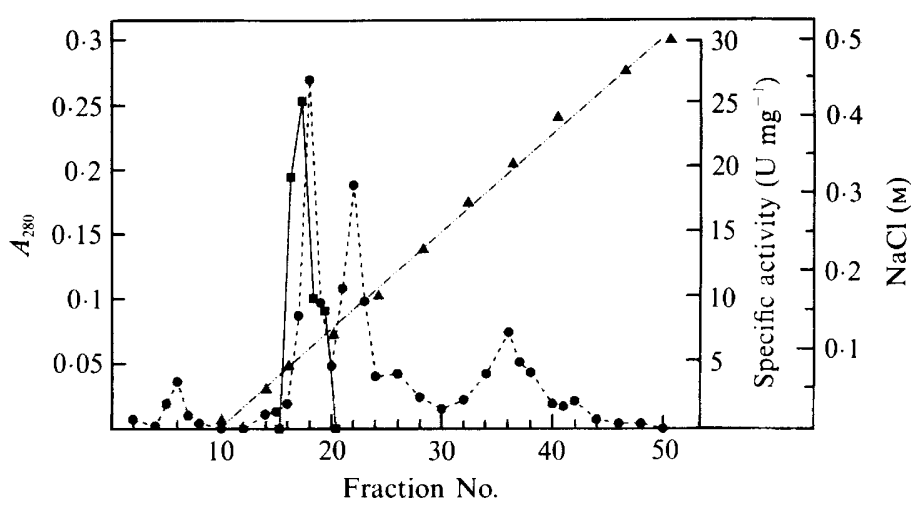

Fig. 1. Anion-exchange chromatography of $P$. stipitis cell extract using a DEAE-Sephacel column. Symbols: $\mathbf{\square}$, xylose reductase activity; $\mathbf{0}$, protein; $\boldsymbol{\Delta}, \mathrm{NaCl}$ gradient. The figure shown is a representative plot chosen from ten independent experiments.

reductase activity of $25.4 \mathrm{U}$ (mg protein $)^{-1}$, an increase of about 51 -fold over that in the cell extract $[0.5 \mathrm{U}(\mathrm{mg}$ protein $)^{-1}$.

Xylose reductase was further purified by gel filtration with a Bio-Sil SEC 125 column. The total enzyme activity recovered after the two chromatographic steps was about $51 \%$ of that in the cell extract. The specific enzyme activity after gel filtration $[43 \cdot 2 \mathrm{U}(\mathrm{mg}$ protein $)^{-1}$ ] represented an 86-fold purification from that in the cell extract. This compares favourably to the 52- and 59-fold purification of the same enzyme reported earlier by Rizzi et al. (1988) and Verduyn et al. (1985), respectively. The purified enzyme had an apparent molecular mass of $62000 \pm 1000 \mathrm{Da}$ as estimated by gel filtration chromatography (data not shown). The molecular mass of the subunits was approximately $38100 \pm 1000$ Da by SDS-PAGE (data not shown). Both are in agreement with previously reported values (Rizzi et al., 1988; Verduyn et al., 1985). Xylose reductase was stable for several weeks at $4{ }^{\circ} \mathrm{C}$ in the presence of $1 \mathrm{~mm}$ $\beta$-mercaptoethanol, but freezing of the purified or partially purified enzyme resulted in immediate and complete loss of activity.

\section{Chemical modification of xylose reductase}

Effect of $\mathrm{pH}$ on the xylose-reductase-catalysed reaction. Yeast xylose reductases have previously been shown to exhibit nearly symmetrical $\mathrm{pH}$-activity profiles, with optima near pH 6.0 under standard assay conditions (Scher \& Horecker, 1966; Suzuki \& Onishi, 1975; Verduyn et al., 1985). These bell-shaped curves suggest that at least two ionizable groups are operative in the catalytic mechanism of yeast xylose reductase. However, if $\mathrm{pH}$ activity profiles are to provide useful information 


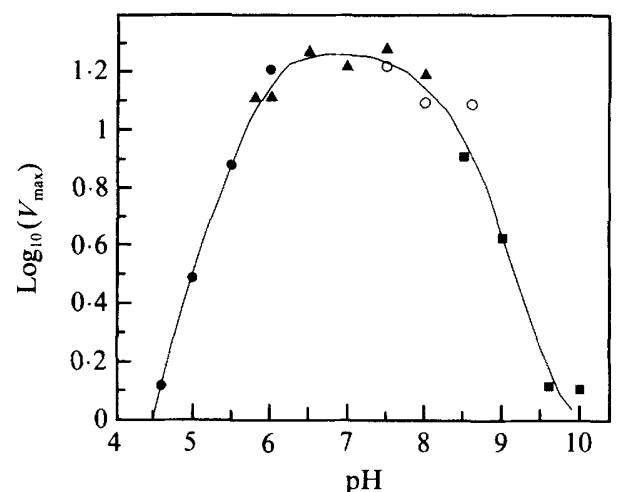

Fig. 2. Effect of $\mathrm{pH}$ on the maximum activity $\left(V_{\max a p p}\right)$ of xylose reductase from $P$. stipitis. Assay buffers used were: $0,100 \mathrm{~mm}$-citric acid/sodium phosphate, $\mathrm{pH} 4.0-6.4 ; \mathbf{\Lambda}, 100 \mathrm{~mm}$-potassium dihydrogen phosphate $/ \mathrm{NaOH}, \mathrm{pH} 5 \cdot 8-8.0 ; \mathrm{O}, \mathrm{Tris} / \mathrm{HCl}, \mathrm{pH} 7 \cdot 5-8.9$, and $\mathbf{\square}$, $100 \mathrm{~mm}$-glycine/ $\mathrm{NaOH}, \mathrm{pH} 8 \cdot 6-10 \cdot 6$. The figure shown is a representative plot chosen from three independent experiments.

on the nature of essential amino acid residues, kinetic analysis at each $\mathrm{pH}$ value is required (Engel, 1977).

Values for $V_{\max a p p}$ (D-xylose) at each $\mathrm{pH}$ were estimated at saturating NADPH $(0.2 \mathrm{~mm})$ concentrations from Eadie-Hofstee plots, and the change in $V_{\text {maxapp }}$ as a function of $\mathrm{pH}$ is plotted in Fig. 2. The $\mathrm{pH}$ activity profile suggests that at least two essential ionizing residues with $\mathrm{p} K_{\mathrm{app}}$ of about 5.8 and 8.1 are required for xylose reductase activity. These estimated $\mathrm{p} K_{\text {app }}$ values are in agreement with the $\mathrm{p} K$ values reported for imidazolium and thiol groups in proteins (Engel, 1977). From this result, we surmised that the essential amino acids might be histidine and cysteine residues. Chemical modification studies on mammalian aldose reductases have also suggested the involvement of histidyl and thiol groups in the enzyme's catalytic mechanisms (Bhatnagar et al., 1989; Cromlish \& Flynn, 1983; Doughty \& Conrad, 1982; Doughty et al., 1982; Flynn et al., 1981; Jedziniak \& Kinoshita, 1971; Liu et al., 1989; Wermuth et al., 1982). Some researchers have suggested that arginyl and lysyl residues may also be involved in aldose reductase activity (Flynn et al., 1989; Doughty \& Conrad, 1982; Doughty et al., 1982). However, the low $\mathrm{p} K_{\text {app }}$ from the basic arm of the $\mathrm{pH}$ activity profile in Fig. 2 does not support the involvement of these groups in yeast xylose reductase activity. To confirm the involvement of histidyl and thiol residues in the catalytic mechanism of xylose reductase, enzyme modification with group-specific inhibitors was undertaken.

\section{Inactivation of xylose reductase by PMBS and DTNB}

Previous studies on yeast xylose reductase (Scher \& Horecker, 1966; Suzuki \& Onishi, 1975; Verduyn et al.,

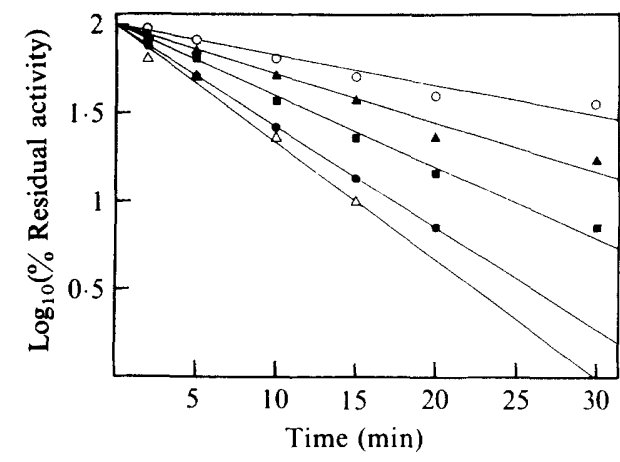

Fig. 3. Kinetics of inactivation of $P$. stipitis xylose reductase by PMBS at various concentrations. The incubation mixture contained enzyme $(0.36 \mu \mathrm{M})$ and PMBS at $5(\mathrm{O}), 7(\mathbf{A}), 10(\mathbf{D}), 15(\mathbf{O})$ or $20(\triangle) \mu \mathrm{M}$. The figure shown is a representative plot chosen from five independent experiments.

1985) and mammalian aldose reductase (Cromlish \& Flynn, 1983; Jedziniak \& Kinoshita, 1971; Liu et al., 1989; Wermuth et al., 1982) have shown that a variety of thiol-modifying reagents can cause almost complete loss of enzyme activity. In the present study when excess PMBS was incubated with the enzyme, a rapid timedependent, concentration-dependent decrease in xylose reductase activity was observed. The semi-logarithmic plots of residual activity as a function of time for the various concentrations of PMBS were linear (Fig. 3), indicating that the inactivation process obeys pseudofirst-order kinetics. The linearity of the plot of $k_{\text {app }}$ $\left(\mathrm{min}^{-1}\right)$ against PMBS concentration indicated that a reversible PMBS-xylose reductase complex was not formed before inactivation (data not shown) (Cardemil, 1987). Analysis of the order of reaction by the method of Levy et al. (1963) resulted in a slope of 0.96 (data not shown), suggesting that at least one PMBS molecule binds to one xylose reductase monomer to effect inactivation. The amino acid sequence of the $P$. stipitis xylose reductase indicates the presence of three cysteine residues per subunit (Amore et al., 1991; Hallborn et al., 1991; Takuma et al., 1991) and the order of reaction determined from our study suggests that one of these residues was modified to effect inactivation.

SDS-PAGE of PMBS-modified xylose reductase showed similar mobility compared to unmodified xylose reductase, indicating that inactivation of the enzyme was not due to cross-linking or aggregation of xylose reductase proteins (data not shown). Inactivation of xylose reductase by PMBS was found to be reversible by treatment with excess $\beta$-mercaptoethanol. To demonstrate reversibility, enzyme was first incubated in the presence of PMBS. At 50 to $60 \mathrm{~min}$, enzyme activity was almost completely (98 to $99 \%$ ) lost (Fig. 4). When $\beta$ mercaptoethanol was added, activity of the PMBS- 


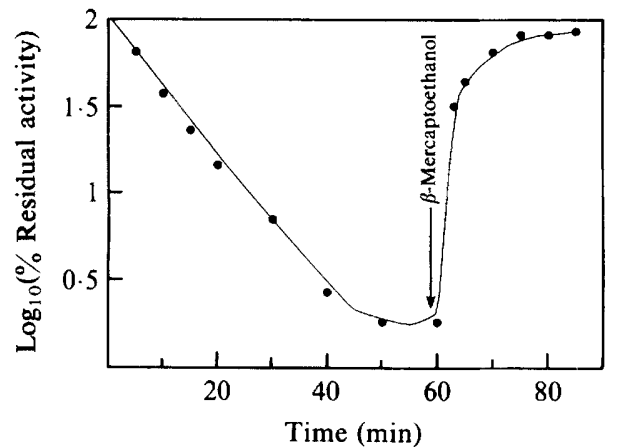

Fig. 4. Reactivation of PMBS-inactivated $P$. stipitis xylose reductase with $\beta$-mercaptoethanol $(1 \mathrm{mM})$. The enzyme $(0 \cdot 36 \mu \mathrm{M})$ was inactivated by PMBS for $60 \mathrm{~min}$, at which time $\beta$-mercaptoethanol was added to the modified enzyme as indicated by the arrow. The figure shown is a representative plot chosen from two independent experiments.

inactivated enzyme was rapidly restored such that within $15 \mathrm{~min}$, about $90 \%$ of the activity was recovered (Fig. 4).

To further characterize the role of essential thiol residue(s) in xylose reductase activity, the protective effect of cofactors, substrates and various analogues on the rate of PMBS inactivation was studied. Maximum protection was provided by NADPH, followed by NADH, while NADP ${ }^{+}$, D-xylose and DL-glyceraldehyde offered no apparent protection (data not shown). Protection by cofactors was concentration-dependent (Fig. 5). A plot of protection as a function of cofactor concentration according to Scrutton \& Utter (1965) could be extrapolated to the origin (Fig. 5, inset), indicating that PMBS inactivation of the enzyme-cofactor complex is not possible.

Protection by cofactors and not by substrates suggests that the critical thiol group may be situated at or near the cofactor-binding site. Similarly, Liu et al. (1989) have suggested cysteine residues in human placental aldose reductase are involved in cofactor binding. Alternatively, formation of the enzyme-cofactor complex may result in conformational changes in the enzyme, thereby making the thiol group inaccessible to PMBS inactivation. The inability of DL-glyceraldehyde and D-xylose to protect the enzyme from inactivation is not surprising as Rizzi et al. (1988) showed earlier that the xylosereductase-catalysed reaction proceeds by an ordered-bibi mechanism with isomerization of a stable enzyme form in which cofactor binds first to form an enzymecofactor complex followed by binding of substrate.

To estimate the number of cysteine groups modified to effect inactivation, the enzyme was treated by DTNB. The enzyme lost about $90 \%$ of initial activity when incubated with DTNB for $10 \mathrm{~min}$. During this period, only one cysteine group per subunit had been modified as estimated by the formation of thionitrobenzoate anions

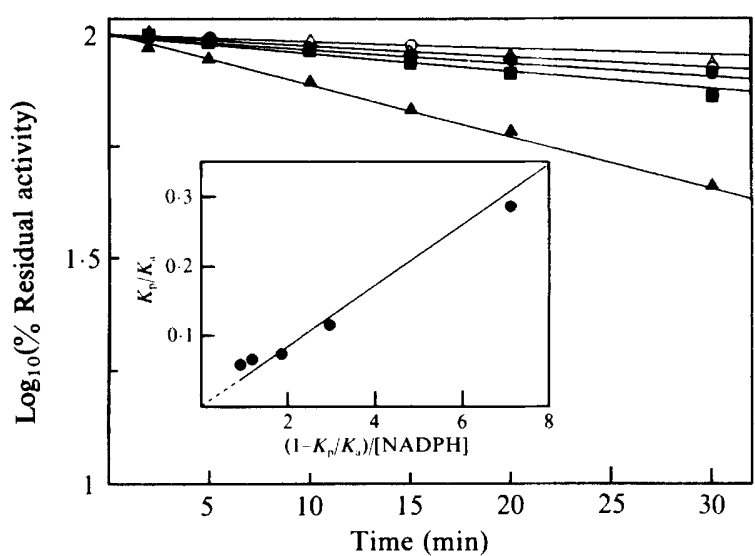

Fig. 5. Protection of $P$. stipitis xylose reductase from PMBS inactivation by NADPH. The incubation mixture contained enzyme $(0.24 \mu \mathrm{M})$ and $1(\triangle), 0.8(O), 0.5(\circlearrowleft), 0.3(\mathbb{0})$ or $0.1(\Delta) \mathrm{mm}-\mathrm{NADPH}$. Inset: the apparent pseudo-first-order rate constants obtained in the presence $\left(K_{\mathrm{p}}\right)$ and the absence $\left(K_{\mathrm{a}}\right)$ of NADPH plotted according to the method of Scrutton \& Utter (1965). The figure shown is a representative plot chosen from two independent experiments.

(data not shown). Prolonged incubation for 70 min led to modification of the other two cysteine groups with a further slight decrease in activity.

\section{Inactivation of xylose reductase by $D E P$}

Xylose reductase was inactivated by DEP in a timedependent and concentration-dependent manner. The linear nature of the semi-logarithmic plots (Fig. 6) indicated that DEP inactivation of xylose reductase obeyed pseudo-first-order kinetics. Plots of $k_{\text {app }}$ versus DEP concentration were linear, indicating that a reversible DEP-enzyme complex was also not formed prior to inactivation (data not shown) (Cardemil, 1987). Analysis of the order of reaction by the method of Levy et al. (1963) resulted in a slope of $1 \cdot 1$ (data not shown), indicating that an average of at least one molecule of DEP binds to one monomer of xylose reductase when inactivation occurs. The amino acid sequence of the enzyme indicates there are six histidyl residues per subunit (Amore et al., 1991; Hallborn et al., 1991; Takuma et al., 1991), the inactivation data suggests that DEP may modify one essential histidine per subunit to effect inactivation. No evidence of cross-linking or aggregation of xylose reductase proteins was observed when DEP-inactivated enzyme was analysed on SDSPAGE (data not shown).

Again, as might be expected for an enzyme reaction which operates according to an ordered-bi-bi mechanism with cofactor binding first (Rizzi et al., 1988), NADPH and NADH protected xylose reductase from modification by DEP. As with the PMBS, cofactor protection from DEP inactivation was concentration-dependent 


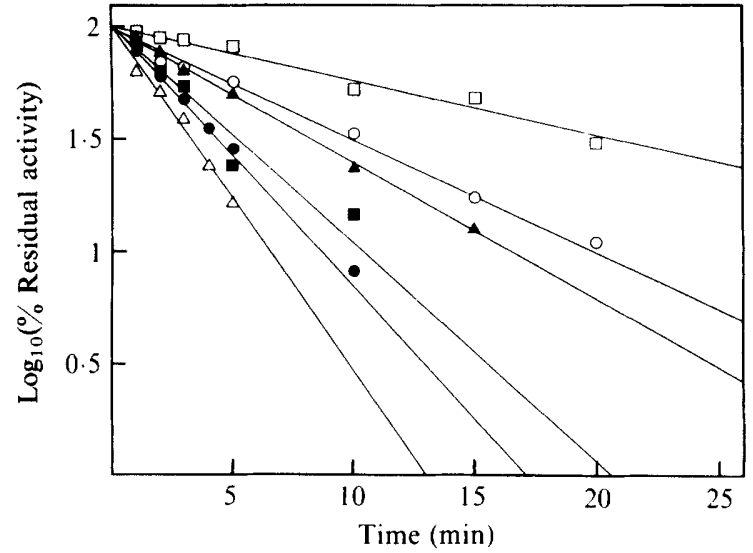

Fig. 6. Kinetics of inactivation of $P$. stipitis xylose reductase by various concentrations of DEP. The incubation mixture contained enzyme $(0 \cdot 24 \mu \mathrm{M})$ and DEP at $0 \cdot 5(\triangle), 0 \cdot 4(\mathbf{O}), 0 \cdot 3(\boldsymbol{\square}), 0 \cdot 2(\boldsymbol{\Delta}), 0 \cdot 15(\mathrm{O})$ or $0 \cdot 1(\square) \mathrm{mm}$. The figure shown is a representative plot chosen from four independent experiments.

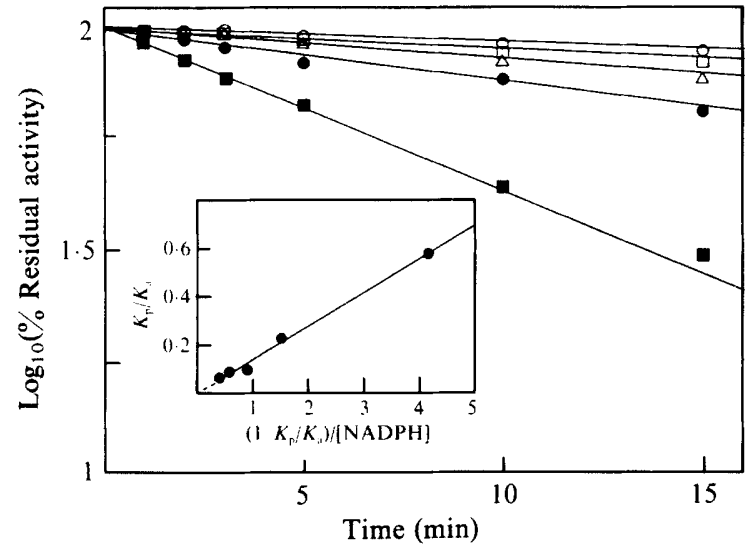

Fig. 7. Protection of $P$. stipitis xylose reductase from DEP inactivation by NADPH. The incubation mixture contained enzyme $(0.36 \mu \mathrm{M})$ in the presence of NADPH at $2.0(O), 1.5(\square), 1.2(\triangle), 1.0(\bigcirc)$ or $0.5(\square) \mathrm{mM}$. Inset: the apparent pseudo-first-order rate constants obtained in the presence $\left(K_{\mathrm{p}}\right)$ and in the absence $\left(K_{\mathrm{a}}\right)$ of NADPH plotted according to the method of Scrutton \& Utter (1965). The figure shown is a representative plot chosen from two independent experiments.

(Fig. 7). When this data was plotted as described by Scrutton \& Utter (1965) it also indicated that DEP inactivation of the enzyme-cofactor complex was not possible (Fig. 7, inset). Again, substrates did not offer any protection to DEP-modification (data not shown). These results suggest that DEP-modification of xylose reductase occurs at or near the cofactor-binding site. This finding agrees with a previous study which suggested that histidyl residues may be responsible for binding of NADPH to bovine, rat and human lens aldose reductase (Doughty \& Conrad, 1982; Doughty et al., 1982). In a closely related enzyme family, the aldehyde reductases, binding of NADPH can cause conformational changes in the enzyme (Davidson \& Flynn, 1979). Likewise, the protection afforded here by the cofactor may be due to conformational changes to the enzyme that rendered the essential histidyl residue inaccessible to DEP.

Although DEP reacts preferentially with histidyl groups, under certain conditions it may also react with lysine, tyrosine, tryptophan and cysteine (Burstein et al., 1974). These reactions with other amino acid groups occur more frequently at high $\mathrm{pH}$ and high DEP concentrations (Miles, 1977); conditions which were not used in this study. Further evidence for the involvement of an essential histidine residue was shown by the ability of neutral hydroxylamine to partially restore the activity of DEP-inactivated xylose reductase. In this experiment, the enzyme was first inactivated almost completely (about $1.5 \%$ residual activity) by incubation in the presence of DEP for $30 \mathrm{~min}$. Addition of neutral hydroxylamine to DEP-inactivated enzyme led to a rapid recovery of about $20 \%$ of enzyme activity in the first $20 \mathrm{~min}$. Further recovery to about $45 \%$ of enzyme activity occurred gradually on incubation for additional 60 min (data not shown). The inability of neutral hydroxylamine to restore enzyme activity fully may be attributed to DEP-modification of other amino acid residues such as lysine which may cause conformational changes in the enzyme (Kersters-Hilderson et al., 1984) or to the irreversible inactivation of some histidyl residues in the presence of excess DEP (Burstein et al., 1974).

Modification of an essential lysine or cysteine residue by DEP can be ruled out since DEP-modification of these residues is not reversed by neutral hydroxylamine (Lenard et al., 1971). Although DEP-modification of histidine and tyrosine residues is reversed by neutral hydroxylamine, evidence of DEP-modification of tyrosine, a decrease in $A_{278}$ (Miles, 1977), was not observed. However, there was an increase in $A_{242}$, and this is indicative of carbethoxylation of histidine residues (data not shown).

This research was supported by grants from the Natural Science and Engineering Research Council of Canada and Stake Technology Limited. We thank M. Bray, A. J. Clarke and J. T. Trevors for helpful discussion and R. L. Stephenson for technical assistance.

\section{References}

Amore, R., Kotter, P., Kuster, C., Ciriacy, M. \& Hollenberg, C. P. (1991). Cloning and expression in Saccharomyces cerevisiae of the NAD(P)H-dependent xylose reductase-encoding gene $(X Y L 1)$ from the xylose-assimilating yeast Pichia stipitis. Gene 109, 89-97.

Bhatnagar, A., Liu, S., Das, B. \& Srivastava, S. K. (1989). Involvement of sulphhydryl residues in aldose reductase-inhibitor interaction. Molecular Pharmacology 36, 825-830.

Bicho, P. A., Runnals, P. L., Cunningham, J. D. \& Lee, H. (1988). Induction of xylose reductase and xylitol dehydrogenase activities in Pachysolen tannophilus and Pichia stipitis on mixed sugars. Applied and Environmental Microbiology 54, 50-54. 
Bolen, P. L., Bietz, J. A. \& Detroy, R. W. (1985). Aldose reductase in the yeast Pachysolen tannophilus: purification, characterization and $\mathrm{N}$-terminal sequence. Biotechnology and Bioengineering Symposium $15,129-148$

Bolen, P. L., Roth, K. A. \& Freer, S. N. (1986). Affinity purifications of aldose reductase and xylitol dehydrogenase from the xylosefermenting yeast Pachysolen tannophilus. Applied and Environmental Microbiology 52, 660-664.

BRADFORD, M. M. (1976). A rapid and sensitive method for the quantitation of microgram quantities of protein utilizing the principal of protein-dye binding. Analytical Biochemistry 72, 248254.

Bruinenberg, P. M., De Bot, P. H. M., VAn Dijken, J. P. \& SCHEFFERS, W. A. (1984). NADH-linked aldose reductase: the key to anaerobic alcoholic fermentation of xylose by yeasts. Applied Microbiology and Biotechnology 19, 256-260.

Burstein, Y., Walsh, K. A. \& Neurath, H. (1974). Evidence of an essential histidine residue in thermolysin. Biochemistry 13, 205210.

CARDEMIL, E. (1987). Kinetics of the chemical modification of enzymes. In Chemical Modification of Enzymes. Active Site Studies, pp. 23-34. Edited by J. Eyzaguirre. Chichester: Ellis Horwood.

Cromlish, J. A. \& FlynN, T. G. (1983). Purification and characterization of two aldose reductase isoenzymes from rabbit muscle. Journal of Biological Chemistry 258, 3416-3424.

Das, B. \& Srivastava, S. K. (1985). Purification and properties of aldose and aldehyde reductase II from human erythrocyte. Archives of Biochemistry and Biophysics 238, 670-679.

DAVIDSON, W. S. \& FLYNN, T. G. (1979). A functional arginine residue in NADPH-dependent aldehyde reductase from pig kidney. Journal of Biological Chemistry 254, 3724-3729.

Ditzelmuller, G., Kubicek, C. P., Wohrer, W. \& Rohr, M. (1984). Xylose metabolism in Pachysolen tannophilus: purification and properties of aldose reductase. Canadian Journal of Microbiology 30 $1330-1336$.

Doughty, C. C. \& ConRAD, S. M. (1982). A reaction mechanism for aldose reductase from lens. Biochimica et Biophysica Acta 708, 358364.

Doughty, C. C., Lee, S., Conrad, S. M. \& Schade, S. (1982). Kinetic mechanism and structural properties of lens aldose reductase. Progress in Clinical and Biological Research 114, 223-242.

Ellman, G. L. (1959). Tissue sulfhydryl groups. Archives of Biochemistry and Biophysics 82, 70-77.

ENGEL, P. C. (1977). Enzyme Kinetics. The Steady-State Approach. London: Chapman and Hall.

Evans, C. T. \& Ratledge, C. (1984). Induction of xylulose-5phosphoketolase in a variety of yeasts grown on D-xylose: the key to efficient xylose metabolism. Archives of Microbiology 139, 48-52.

FlynN, T. G., Ferguson, D. \& Davidson, W. S. (1981). Functional groups in pig kidney aldehyde reductase. In Function and Regulation of Monoamine Enzymes: Basic and Clinical Aspects, pp. 601-610. Edited by E. Usdin, N. Weiner \& M. Youdin. New York: Macmillan Press.

Flynn, T. G., Charington, B., Lyons, C., Chao, H., Hyndman, D. \& MoRJANA, N. (1989). Chemical modification of aldehyde and aldose reductase by pyridoxal 5'-phosphate. In Enzymology and Molecular Biology of Carbonyl Metabolism 2, pp. 251-264. Edited by H. Weiner and T. G. Flynn. New York: Alan R. Liss.

HAGEDORN, J. \& CIRIACY, M. (1989). Isolation and characterization of $x y l$ mutants in a xylose-utilizing yeast, Pichia stipitis. Current Genetics 16, 27-33.

Hallborn, J., Walfridsson, M., Airaksinen, U., Ojamo, H., HahnHagerdal, B., Penttila, M. \& Keranen, S. (1991). Xylitol production by recombinant Saccharomyces cerevisiae. Bio/Technology 9, 1090-1095.

Ho, N. W. Y., Lin, F. P., Huang, S., ANDRews, P. C. \& TSaO, G. T. (1990). Purification, characterization, and amino terminal sequence of xylose reductase from Candida shehatae. Enzyme and Microbial Technology 12, 33-39.

JEDZINIAK, J. A. \& KinoshitA, J. H. (1971). Activators and inhibitors of lens aldose reductase. Investigative Ophthalmology 10, 357-366.
Kador, P. F., Sharpless, N. E. \& Kinoshita, J. H. (1985). Aldose reductase inhibitors: A potent new class of agents for the pharmacological control of certain diabetic complications. Journal of Medicinal Chemistry 28, 841-849.

Kersters-Hilderson, H., Van Doorslaer, E., Lippens, M. \& De BRUYNE, C. K. (1984). The pH dependence and group modification of $\beta$-D-xylosidase from Bacillus pumilus: Evidence for sulphhydryl and histidyl groups. Archives of Biochemistry and Biophysics 234, 6172.

LAEMmLI, U. K. (1970). Cleavage of structural proteins during the assembly of the head of bacteriophage T4. Nature, London 227, 680685

Lee, H., James, A. P., Zahab, D. M., Mahmourides, G., Maleszka, R. \& SCHNEIDER, H. (1986). Mutants of Pachysolen tannophilus with improved production of ethanol from D-xylose. Applied and Environmental Microbiology 51, 1252-1258.

Lenard, N. J., McDonald, J. J., Henderson, R. E. L. \& ReichmanN, M. E. (1971). Reaction of diethyl pyrocarbonate with nucleic acid components. Adenosine. Biochemistry 10, 3335-3342.

LEVY, H. M., Leber, P. D. \& RYAN, E. M. (1963). Inactivation of myosin by 2,4-dinitrophenol and protection by adenosine triphosphate and other phosphate compounds. Journal of Biological Chemistry 238, 3654-3659.

Liu, S., Bhatnagar, A., Das, B. \& Srivastava, S. K. (1989). Functional cysteinyl residues in human placental aldose reductase. Archives of Biochemistry and Biophysics 275, 112-121.

MILES, E. W. (1977). Modification of histidyl residues in proteins by diethylpyrocarbonate. Methods in Enzymology 47, 431-443.

Rizzi, M., Erlemann, P., Bui-Thanh, N.-A. \& Dellweg, H. (1988), Xylose fermentation by yeasts 4 . Purification and kinetic studies of xylose reductase from Pichia stipitis. Applied Microbiology and Biotechnology 29, 148-154.

SCHER, B. M. \& HoreCKer, B. L. (1966). Pentose metabolism in Candida III. The triphosphopyridine nucleotide-specific polyol dehydrogenase of Candida utilis. Archives of Biochemistry and Biophysics 116, 117-128.

SCHNEIDER, H. (1989). Conversion of pentoses to ethanol by yeasts and fungi. Critical Reviews in Biotechnology 9, 1-40.

Schneider, H., Lee, H., Barbosa, M. DE F. S., Kubicek, C. P. \& JAMEs, A. P. (1989). Physiological properties of a mutant of Pachysolen tannophilus deficient in NADPH-dependent D-xylose reductase. Applied and Environmental Microbiology 55, 2877-2881.

SCRutTon, M. \& UTTER, M. (1965). Pyruvate carboxylase V. Interaction of the enzyme with adenosine triphosphate. Journal of Biological Chemistry 240, 3714-3723.

Skoog, K. \& HahN-Hagerdal, B. (1988). Xylose fermentation. Enzyme and Microbial Technology 10, 66-80.

SUZUKI, T. \& ONISHI, H. (1975). Purification and properties of polyol: NADP oxidoreductase from Pichia quercuum. Agricultural and Biological Chemistry 39, 2389-2397.

Takuma, S., NaKaShima, N., TantirungkiJ, M., Kinoshita, S., OKada, H., SeKi, T. \& Yoshida, T. (1991). Isolation of xylose reductase gene of Pichia stipitis and its expression in Saccharomyces cerevisiae. Applied Biochemistry and Biotechnology 28/29, 327-340.

VERdUYN, C., VAN KLEEF, R., Frank, J., SChreUder, H., VAN DiJKen, J. P. \& Scheffers, W. A. (1985). Properties of the NAD(P)Hdependent xylose reductase from the xylose-fermenting yeast Pichia stipitis. Biochemical Journal 226, 669-677.

Watson, J. A., Hayashi, J. A., Schuytema, E. \& Doughty, C. C. (1969). Identification of reduced nicotinamide adenine dinucleotide phosphate-dependent aldehyde reductase in a Rhodotorula strain. Journal of Bacteriology 100, 110-116.

WeBB, S. R. \& LEE, H. (1990). Regulation of D-xylose utilization by hexoses in pentose-fermenting yeasts. Biotechnology Advances 8, 685697

WEBB, S. R. \& LEE, H. (1991). Inhibitors of xylose reductase from the yeast Pichia stipitis. Applied Biochemistry and Biotechnology 30, 325337.

Wermuth, B., Burgisser, H., Bohren, K. \& van Wartburg, J. A. (1982). Purification and characterization of human brain aldose reductase. European Journal of Biochemistry 127, 279-284. 